\title{
BMJ Open Employment status and psychological distress in a population-based cross-sectional study in Sweden: the impact of migration
}

\author{
Anna Sidorchuk, ${ }^{1}$ Karin Engström, ${ }^{1,2}$ Charisse M Johnson, ${ }^{1}$ Naima Kayser \\ Leeoza, ${ }^{1}$ Jette Möller ${ }^{1}$
}

To cite: Sidorchuk A, Engström K, Johnson CM, et al. Employment status and psychological distress in a population-based cross-sectional study in Sweden: the impact of migration. BMJ Open 2017;7: e014698. doi:10.1136/ bmjopen-2016-014698

- Prepublication history for this paper is available online. To view these files please visit the journal online (http://dx.doi.org/10.1136/ bmjopen-2016-014698).

Received 11 October 2016 Revised 17 January 2017 Accepted 8 February 2017

CrossMark

\footnotetext{
${ }^{1}$ Department of Public Health Sciences, Karolinska Institutet, Stockholm, Sweden

${ }^{2}$ Centre of Epidemiology and Community Medicine, Stockholm County Council, Stockholm, Sweden
}

Correspondence to Dr Anna Sidorchuk; anna.sidorchuk@ki.se

\section{ABSTRACT \\ Objectives: Unemployment and temporary}

employment are known to impact psychological health. However, the extent to which the effect is altered by migration-related and sociodemographic determinants is less clear. The purpose of this study was to investigate whether the association between employment status and psychological distress differs between immigrants and Swedish-born and to what extent, the association is modified by gender and reason for immigration.

Design: Cross-sectional survey study.

Participants and setting: Data from public health surveys undertaken in 2002, 2006 and 2010 from random samples of Stockholm County residents, Sweden, were used to analyse a weighted sample of 51118 individuals aged 18-64 (43 444 Swedish-born, 4055 non-refugees, 3619 refugees). According to their activity in the labour market, the participants were categorised into permanently/self-employed, temporarily employed and unemployed.

Outcomes measures: Associations between selfreported employment and psychological distress measured by a 12-item version of the General Health Questionnaire were explored across individuals with different migration status and reasons for immigration using logistic regression and pairwise comparisons. The analyses were stratified by gender and adjusted for age, socioeconomic characteristics and survey year.

Results: Unemployment was associated with elevated likelihood of psychological distress across the study population, regardless of migration status and gender. Fully adjusted models revealed nearly a 3-fold higher odds of distress in unemployed Swedish-born (OR $3.05,95 \% \mathrm{Cl} 2.66$ to 3.51 ), non-refugees (OR 3.51 , $95 \% \mathrm{Cl} 2.44$ to 5.05 ) and refugees (OR 2.91, 95\% Cl 2.20 to 3.85 ) when compared with permanently/selfemployed. Temporary employment also increased the likelihood of distress, particularly among refugees and Swedish-born.

Conclusions: The effect of unemployment on increased likelihood of poor psychological well-being overcomes gender-specific and migration-specific differences and is equally pronounced for Swedishborn, non-refugees and refugees. Exclusion from the
Strengths and limitations of this study

- The large population-based sample with selfreported and register-based data ensures statistical power in the analyses stratified by migration status, reasons for immigration and gender.

- The use of an intercultural-validated measure of psychological distress diminishes the impact of information bias, while high participation rate observed among immigrants reduces the risk of selection bias.

- The application of survey weights allows generalisability of the study results for Stockholm residents, who, in turn, are representative to other multiethnical urban populations in Sweden.

- The cross-sectional study design restricts testing temporality of study covariates and, therefore, prevents from making causal inferences and limits disentangling confounding and mediating effects.

- As the reason for immigration variable is constructed based on the country of origin and year of immigration to Sweden, misclassification may occur if individuals from asylum-seeking countries entered Sweden on other grounds.

labour market appears to be a major determinant of psychological health inequalities in contemporary Sweden.

\section{INTRODUCTION}

Psychological distress is commonly viewed as a non-specific mental health problem and a state of emotional disturbance varying in severity and impairing social functioning and day-to-day living activities. ${ }^{1}$ It has recently become a public health concern due to its high and increasing prevalence ranging from $13 \%$ to $35 \%$ in European countries, ${ }^{2}{ }^{3}$ with Sweden falling in the middle of the 
spectrum. ${ }^{4-7}$ Scientific evidence links impaired psychological well-being to the increased risk of disability, absenteeism, loss of productivity and social deprivation. ${ }^{689}$ Yet, the results of empirical studies on sociodemographic correlates of psychological distress remain inconsistent ${ }^{1}$ and two major social determinants that deserve close attention are labour market activity and migration status.

Systematic reviews portray unemployed ${ }^{10}{ }^{11}$ and temporarily employed individuals ${ }^{12} 13$ to be at increased risk of psychological distress as a result of the direct impact of financial strain and indirect effects of downgraded social role, along with facing persistent job insecurity as a chronic stressor. ${ }^{10-12}{ }^{14}$ Flint $e t$ al ${ }^{15}$ provide evidence that the negative health effects of downward transition from secure to insecure employment or unemployment are larger than the positive effects of upward transition. The mechanisms and manifestations of psychological distress are considered to be gender-specific, with a lower prevalence in men. ${ }^{16}$ However, if coupled with unemployment, the results become less consistent, reflecting an interaction with perceived role as resource providers. ${ }^{2}{ }^{17}$ The review by van Rijn $e t$ a ${ }^{9}$ proposes a possible bidirectional relationship between psychological distress and labour market exclusion with elevated risk of future unemployment among those with poor psychological health. Thus, the hypotheses of social causation (labour market marginalisation and exclusion negatively impacting psychological well-being) and social selection (poor mental health increasing the risk of unemployment) could conceptualise the relationship between employment status and mental health. In Sweden, a resilient economy, high employment rate and egalitarian approach to welfare policies can be expected to buffer the negative health effects of employment instability and labour market marginalisation. However, Swedish studies report psychological distress to be considerably more common in unemployed and those experiencing employment precariousness compared with their permanently employed counterparts. ${ }^{714} 18$

Migration is a stressful life event as it encompasses managing premigration circumstances, often traumatic in the case of refugees, with challenging postmigration integration into a host society. Studies on migrants' psychological well-being vary in their results reflecting extensive heterogeneity towards ethnicity, migrationrelated conditions and socioeconomic determinants, ${ }^{18-23}$ but acknowledge higher vulnerability of immigrants to mental health challenges stemming from exposure to migration process compounded by social and financial adversity, underuse of healthcare services and discrimination. In Sweden, through several waves of immigration for economic and humanitarian reasons, a proportion of foreign-born population steadily increased from $4.0 \%$ in 1960 to $11.3 \%$ in 2000 and to $17.0 \%$ in $2015^{24}$ exceeding corresponding statistics for Europe $(10.0 \%$ in 2015) and neighbouring Northern European countries $\left(13.0 \%\right.$ in 2015). ${ }^{25}$ To date, Sweden is receiving a large influx of immigrants, which makes the issue of integration one of the most important governmental and public concerns. According to the United Nation report, most of immigrants to Sweden are of working age (median age of 41 years $^{25}$ ), which emphasises the employment with its net effect on cultural, language and social skills, as a core aspect of integration. ${ }^{26}$ The Swedish migration and integration policy aims at equal labour market opportunities to all with no differences in employment, unemployment and wages in relation to the individual's origin that goes along with the overarching national public health goal of creating social conditions for a good health for the entire population. However, a Swedish study on immigrants' labour market activity highlights considerable differences in employment rates within the immigrant population, revealing foreign-born non-Europeans, women and refugees to be worse-off. ${ }^{27}$

Whether the effect of employment status on psychological well-being is altered by migration-related factors is a question that deserves further attention. Reviews and national-wide studies provided evidence of the association between employment, immigrant status and severe mental disorders, ${ }^{28-30}$ while empirical data on corresponding associations with psychological distress, particularly with regard to large population-based studies, are relatively scarce with a certain variability in results owing primarily to heterogeneity in ethnicity of immigrant groups. ${ }^{19} 3132$ The moderating effect of refugee and non-refugee immigration requires separate consideration as, in addition to abovementioned differences in labour market involvement, refugees demonstrate substantially higher risk of mental disorders compared with other immigrants and natives. ${ }^{33} 34$ To contribute to better understanding the epidemiological features of psychological distress in contemporary Swedish society, we aimed to determine whether the association between employment status and psychological distress differs between immigrants (ie, persons with foreign country of origin; henceforth 'immigrants') and Swedish-born as well as to what extent the effect is modified by gender and reason for immigration.

\section{METHODS}

\section{Study population}

Cross-sectional data were obtained from public health surveys undertaken in 2002, 2006 and 2010 from areastratified, random samples of Stockholm County residents aged 18 and above $\left(n=88\right.$ 169). ${ }^{35}$ Mailed surveys collected data on various parameters of self-rated health and well-being along with information on demographic, socioeconomic and lifestyle circumstances, including labour market activity. Data were further linked to health and administrative registers. To account for non-response and sampling methods, calibrated weights were computed for survey data by Statistics Sweden, using register-based data on sex, age, 
country of birth, civic status, income, educational level, sickness allowance and area of residence as auxiliary variables. ${ }^{35}$ An attempt to overcome under-representation of immigrants was made by translating the 2006 questionnaire into the six most commonly spoken foreign languages in Sweden. ${ }^{36}$

We pooled baseline data for respondents to the three surveys who were of active working age (ie, aged 18-64) and indicated their ties to labour market as either being employed (permanently employed, temporarily employed or self-employed) or unemployed ( $\mathrm{n}=56202)$. Based on completeness of information on migration status, we excluded 1122 adopted individuals due to the dilemma of placing them into a particular category and as health-related heterogeneity is common among adoptees resulting from various exposures to preadoption factors. ${ }^{37}$ Another 461 respondents were excluded due to missing or unclear migration data. To avoid assessing mental health impacted by premigration circumstances, known to be substantial stressors per se, rather than by labour market activity, we excluded immigrants who were hospitalised for mental disorders within 2 years after entering Sweden, according to the National Patient Register $(n=63)$. The analytical sample, thus, consisted of 54556 respondents, of which 8773 were immigrants (figure 1).

\section{Psychological distress}

Psychological distress was measured by a 12 -item version of the General Health Questionnaire (GHQ-12), ${ }^{38}$ which is proven to be equal to other GHQ versions independent of cultural context and language. ${ }^{39-41}$ GHQ-12 is used in studies on unemployment ${ }^{2}{ }^{15}$ and migrant health ${ }^{42}$ as a reliable and validated screening measurement of mental health status and well-being. GHQ-12 provides information on how the respondents felt during the past few weeks in relation to the following items: able to concentrate, lost sleep over worries, playing a useful part in society, capable of making decisions, constantly under strain, could not overcome difficulties, enjoy normal day-to-day activities, face up to problems, feel unhappy and depressed, losing confidence in yourself, thinking of yourself as worthless person, feeling reasonably happy. ${ }^{1} 38$ Following the standard of assessing GHQ-12, we rated each item dichotomously as 0 if the responses were 'better than usual/as usual' or 1 if answered as 'worse than usual/ much worse than usual' and then summed the scores. Individuals providing answers to, at least, nine items were considered as respondents to GHQ-12. Applying the 'caseness threshold' of 3 generally used for GHQ- $12^{40}$ and validated for the Swedish population, ${ }^{74}$ we considered individuals scoring 3 or more as having psychological distress and used this cut-off for the main analysis. To better address the outcome severity, ${ }^{39}{ }^{44}$ in a sensitivity analysis, we utilised an alternative cut-off score of 7 or more. ${ }^{5} 45$

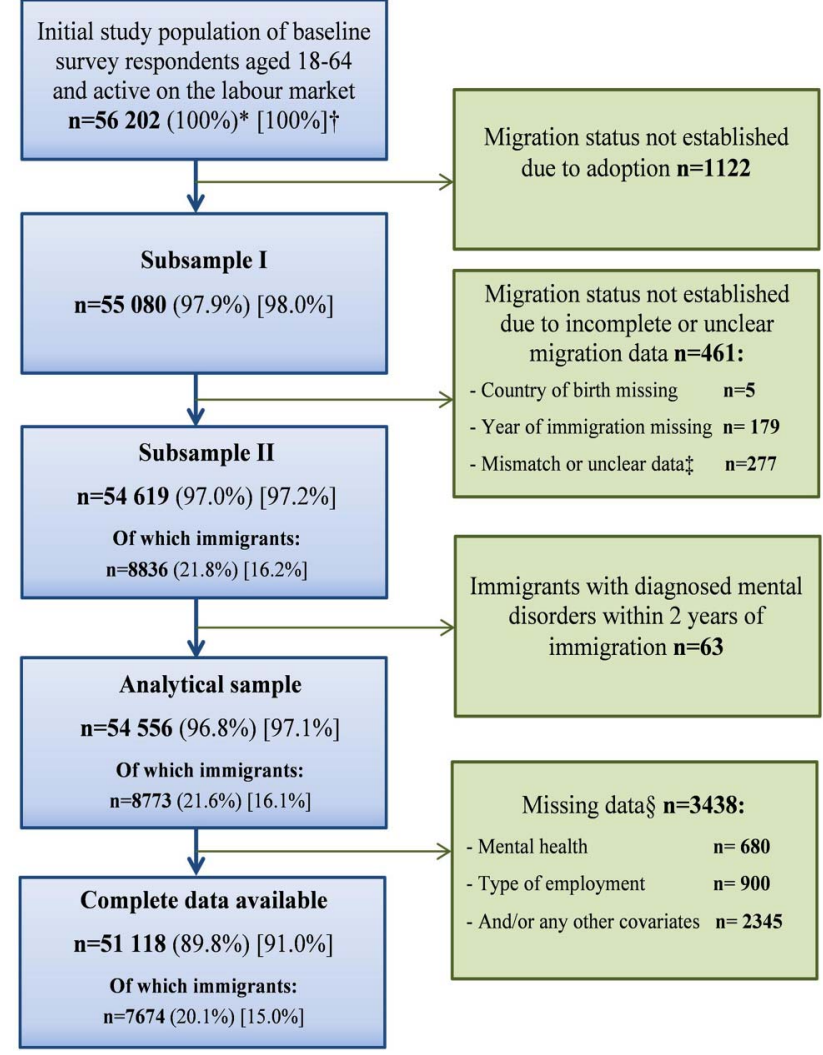

Figure 1 Flow chart of the selection process of 56202 respondents to the Stockholm County Public Health surveys in 2002, 2006 and 2010 with proportions weighted for non-response and sampling methods (\%) and unweighted (\%). *Proportions in parentheses are weighted for non-response and sampling methods using calibrated weights computed for survey data by Statistics Sweden. †Proportion in squared brackets are unweighted. $\ddagger$ Native Swedes with first migration data recorded as 'immigration' or foreign-born persons with information not fulfilling criteria for establishing reasons for immigration to Sweden. §Missing data for separate variables do not add up to 3438 as several items can be missing for the same individual.

\section{Employment status}

By answering the survey question: 'Which of the following alternatives apply to you right now?', the respondents stated their major current activity by choosing between 11 response alternatives: permanent employment; temporary employment; self-employed; on sick-leave for more than 30 days; disability pensioner/receiving sickness or activity benefits; old-age pensioner; leave of absence, including studies and parental leave; student/ trainee; unemployed; managing the household; and other. As the study sample was restricted to individuals active in the labour market, we categorised employment status as 'permanently/self-employed' (the reference), 'temporarily employed' and 'unemployed'. Self-employed characterises those with their own business or who are a business partner and is considered as similar in nature to permanent employment. Thus, selfemployment and permanent employment conditions 
are seen as non-precarious with similar, though not identical, working hours and social security regimes. ${ }^{46}$ Additionally, self-employed and permanently employed individuals might be considered as having relatively high job control, which is known to be protective against impaired mental health and well-being. ${ }^{47}$

\section{Migration status and reason for immigration}

Based on the country of birth obtained through the Total Population Register, we dichotomised migration status as 'Swedish-born' (the reference) and 'immigrants'. Register data on reason for immigration are not available. Instead, information about calendar year of immigration to Sweden was used in combination with country of birth to designate immigrants as 'refugees' and 'non-refugees'. The historical trends in Swedish policies related to immigration for labour and humanitarian purposes were used as a theoretical basis for defining reason for immigration. The robustness of designation was tested with Statistics Sweden and the Swedish Migration Board. Study participants were regarded as 'refugees' if country of birth and year of immigration matched that of asylum-seekers to Sweden. 'Non-refugees' were identified as individuals that immigrated to Sweden from countries which had guest worker programmes with Sweden or as originating from a non-asylum-seeking country.

\section{Demographic and socioeconomic characteristics}

Several socioeconomic characteristics, namely attained education, disposable family income and socioeconomic position (SEP), have been considered as potential confounders based on the theoretical model of causal mechanisms of social inequality in health ${ }^{48}$ as well as on empirical data on mental health in relation to unemployment $^{2} \quad 49 \quad 50$ and migrant health. ${ }^{19} \quad 31 \quad 32$ Information on education and income was retrieved from the Longitudinal Integration Database for Medical Insurance and Labour Market Studies at the year of survey or the closest year available. Attained education was categorised into 'low' (completed compulsory school; the reference), 'medium' (completed high school or vocational training) and 'high' (university). The disposable family income was divided into quintiles (with the highest quintile used as the reference) representing the annual disposable income of a household after taking into account expenses related to taxes, family size and constellation. Survey-based SEP, defined by current occupation or, if unemployed, by the previous occupation, was categorised as 'high level salaried employee' (the reference), 'medium level salaried employee', 'low level salaried employee', 'self-employed', 'skilled worker' and 'unskilled worker'. Demographic characteristics included gender and age as dichotomous and continuous variables, respectively, and were retrieved from the Total Population Register. To address the period effect, the calendar year of survey was taken into consideration in the analyses with the year 2002 used as the reference.

\section{Statistical analysis}

We used the survey design procedure and applied the weights for sampling methods and survey non-response, while Taylor linearisation was utilised to calculate the SEs. All reported results present weighted estimates, unless mentioned otherwise.

For descriptive purposes, we performed weighted bivariate analysis with the Pearson $\chi^{2}$ statistic for categorical variables and multiple-sample multivariate tests on means for continuous variables using the Wald test. Logistic regression models were fitted to obtain ORs and corresponding $95 \%$ CIs stratified by migration status, reason for immigration and gender. Variables fulfilling the criteria for confounders, or if found significant in univariate analysis, were controlled for. As the crosssectional design restricts from assessing potential mediation, we used the stepwise approach to avoid possible overadjustment. Thus, the initial adjustment for age and gender (Model 1; only age in gender-stratified analyses) was followed by adjustment for education (Model 2) and then for SEP, disposable family income and the survey year (Model 3).

To overcome the problem with interpreting the significance of interaction effects on the multiplicative scale in non-linear models where such effects are relative to the baseline odds of independent variables and may differ for different values of study covariates, ${ }^{51}{ }^{52}$ we performed a pairwise comparison and marginal effect estimation. We assessed the effect of each category of employment status on the probability of having psychological distress if migration status and reason for immigration change from 'Swedish-born' to 'non-refugees' and to 'refugees' as well as gender from 'men' to 'women'. Models simultaneously controlled for all covariates using the Bonferroni coefficient to account for multiple comparisons.

Among the 54556 individuals, information on 1 or more variables was missing in $3438(6.3 \%)$ participants. Psychological distress and employment status were unavailable for $680(1.2 \%)$ and $900(1.6 \%)$ respondents, respectively, and 2345 (4.3\%) individuals were missing information on potential confounders. The Pearson $\chi^{2}$ statistic was used for missing data analysis. Main analyses and pairwise comparison were based on individuals with complete information for all abovementioned covariates, that is, 51118 participants (figure 1).

Sensitivity analysis was performed by using a cut-off of 7 and more symptoms of distress, utilising the same modelling as the main analyses. The second sensitivity analysis was conducted to account for a potential confounding effect of family structure, which is known to be related to employment and psychological health. ${ }^{2}$ Survey-based family structure variable was categorised into 'adults with children' (the reference), 'adults without children', 'alone with children' and 'alone 
Table 1 Demographic characteristics of 51118 individuals with data available for all covariates: the Stockholm County public health surveys, 2002,2006 and 2010

\begin{tabular}{|c|c|c|c|c|c|c|c|}
\hline \multirow[b]{2}{*}{$\begin{array}{l}\text { Characteristics (\% and mean } \\
\text { weighted)‡ }\end{array}$} & \multirow[b]{2}{*}{$\begin{array}{l}\text { Total sample } \\
(\mathrm{n}=51118)\end{array}$} & \multicolumn{3}{|l|}{ Employment status ${ }^{\star}$} & \multicolumn{3}{|c|}{$\begin{array}{l}\text { Migration status and reason for } \\
\text { immigrationt }\end{array}$} \\
\hline & & $\begin{array}{l}\text { Permanently/self-employed } \\
(n=44 \text { 493) }\end{array}$ & $\begin{array}{l}\text { Temporarily } \\
\text { employed }(n=4972)\end{array}$ & $\begin{array}{l}\text { Unemployed } \\
(n=1653)\end{array}$ & $\begin{array}{l}\text { Swedish-born } \\
(n=43444)\end{array}$ & $\begin{array}{l}\text { Non-refugees } \\
(n=4055)\end{array}$ & $\begin{array}{l}\begin{array}{l}\text { Refugees } \\
(n=3619)\end{array} \\
\end{array}$ \\
\hline \multicolumn{8}{|l|}{ Gender } \\
\hline Men & 52.3 & 53.6 & 42.6 & 52.2 & 52.5 & 47.3 & 55.4 \\
\hline Women & 47.7 & 46.4 & 57.4 & 47.8 & 47.5 & 52.7 & 44.6 \\
\hline Age, mean (SD) & $41.6(11.8)$ & $42.7(11.5)$ & $34.1(11.1)$ & $40.3(12.2)$ & $41.2(12.4)$ & $45.5(9.7)$ & $41.5(8.4)$ \\
\hline \multicolumn{8}{|l|}{ Education } \\
\hline High & 28.9 & 29.1 & 29.9 & 21.9 & 28.8 & 29.5 & 29.0 \\
\hline Medium & 38.4 & 38.0 & 42.0 & 35.1 & 39.6 & 30.2 & 36.1 \\
\hline Low & 32.7 & 32.9 & 28.1 & 43.0 & 31.6 & 40.3 & 34.9 \\
\hline \multicolumn{8}{|l|}{ Socioeconomic position } \\
\hline High-level salaried employee & 22.1 & 23.0 & 18.0 & 13.0 & 23.8 & 17.4 & 13.0 \\
\hline Medium-level salaried employee & 24.7 & 25.2 & 23.0 & 20.4 & 26.0 & 21.9 & 17.7 \\
\hline Low-level salaried employee & 13.5 & 13.3 & 13.9 & 17.6 & 14.3 & 12.5 & 8.8 \\
\hline Self-employed & 10.8 & 12.4 & 1.6 & 2.4 & 10.6 & 11.8 & 11.7 \\
\hline Skilled worker & 11.9 & 11.2 & 14.9 & 16.9 & 10.9 & 15.0 & 16.6 \\
\hline Unskilled worker & 17.0 & 14.9 & 28.6 & 29.7 & 14.4 & 21.4 & 32.2 \\
\hline \multicolumn{8}{|l|}{ Disposable family income } \\
\hline Very high & 22.2 & 24.6 & 8.3 & 10.0 & 24.5 & 16.4 & 9.9 \\
\hline High & 22.6 & 24.0 & 15.9 & 11.6 & 23.6 & 21.8 & 16.1 \\
\hline Medium & 20.1 & 20.1 & 21.4 & 15.5 & 20.3 & 20.5 & 17.8 \\
\hline Low & 17.1 & 16.0 & 23.7 & 22.9 & 16.7 & 18.3 & 19.1 \\
\hline Very low & 18.0 & 15.3 & 30.7 & 40.0 & 14.9 & 23.0 & 37.1 \\
\hline \multicolumn{8}{|l|}{ Psychological distress } \\
\hline No (GHQ-12 scoring <3) & 79.5 & 81.6 & 71.7 & 57.4 & 80.2 & 81.0 & 73.4 \\
\hline Yes (GHQ-12 scoring $\geq 3$ ) & 20.5 & 18.4 & 28.3 & 42.6 & 19.8 & 19.0 & 26.6 \\
\hline \multicolumn{8}{|l|}{ Severe psychological distress } \\
\hline No (GHQ-12 scoring <7) & 92.8 & 93.8 & 89.9 & 80.2 & 93.3 & 92.3 & 89.5 \\
\hline Yes (GHQ-12 scoring $\geq 7$ ) & 7.2 & 6.2 & 10.1 & 19.8 & 6.7 & 7.7 & 10.5 \\
\hline \multicolumn{8}{|l|}{ Employment status } \\
\hline Permanently/self-employed & 84.9 & NA & NA & NA & 86.1 & 84.9 & 76.0 \\
\hline Temporarily employed & 11.3 & NA & NA & NA & 10.8 & 10.7 & 15.8 \\
\hline Unemployed & 3.8 & NA & NA & NA & 3.1 & 4.4 & 8.2 \\
\hline \multicolumn{8}{|c|}{ Migration status/reason for immigration } \\
\hline Swedish-born & 80.0 & 81.1 & 76.3 & 66.1 & NA & NA & NA \\
\hline Non-refugees & 9.5 & 9.5 & 9.0 & 11.1 & NA & NA & NA \\
\hline Refugees & 10.5 & 9.4 & 14.7 & 22.8 & NA & NA & NA \\
\hline
\end{tabular}




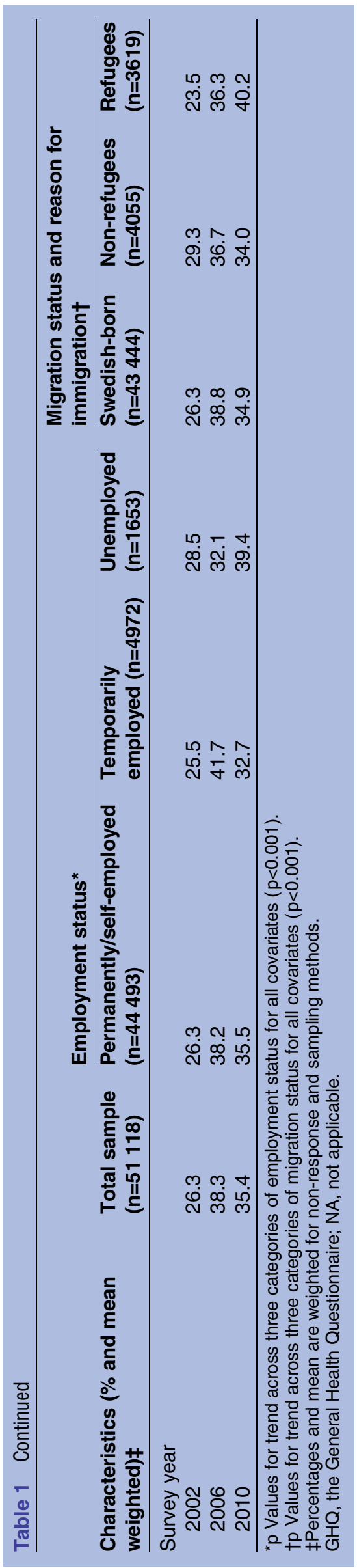

without children', but not included in the main analysis due to a large amount of missing data. The second analysis was, thus, performed in 47582 individuals with data available for all variables, including family structure. All analyses were conducted using Stata/MP V.13.1 (Stata Corp., College Station, Texas, USA).

\section{Ethical considerations}

All respondents gave informed consent for participation and register linkage.

\section{RESULTS}

Table 1 presents the distribution of covariates by employment and migration status. In the weighted sample, $11.3 \%$ and $3.8 \%$ of the respondents reported being temporarily employed or unemployed, respectively. Refugees and non-refugees were equally represented in the study sample $(10.5 \%$ and $9.5 \%$, respectively). In total, every fifth person reported psychological distress (GHQ scoring $\geq 3$ ). The prevalence was higher in unemployed $(42.6 \%)$ compared with permanently/self-employed $(18.4 \%) \quad(p<0.001)$. Likewise, refugees were more likely to report distress $(26.6 \%)$ compared with Swedish-born $(19.8 \%)(\mathrm{p}<0.001)$.

In the univariate analysis, immigrants had a higher likelihood of psychological distress compared with Swedish-born (OR 1.20, 95\% CI 1.13 to 1.29). Stratification by reason for immigration eliminated differences in distress between non-refugees and Swedish-born (OR $0.95,95 \%$ CI 0.87 to 1.04 ), but considerably strengthened the corresponding association for refugees (OR $1.47,95 \%$ CI 1.35 to 1.60 ). In addition, female gender was found to be strongly associated with psychological distress (OR 1.63, 95\% CI 1.54 to 1.71) (data not shown).

Unemployment and temporary employment were associated with an elevated likelihood of distress, regardless of migration status and reasons for immigration (table 2). Nearly threefold higher odds of distress were demonstrated for unemployed compared with their permanently/self-employed counterparts. Adjustment for demographic and socioeconomic covariates and survey year marginally impacted these associations.

In gender-stratified fully adjusted models, psychological distress remains significantly associated with unemployment and temporary employment in Swedish-born and immigrant men and women (table 3). As an exception, elevated likelihood of distress in temporarily employed non-refugee men and women seen in the unadjusted model decrease after adjustment for study covariates.

Pairwise comparisons between categories of employment status, reason for immigration and gender revealed an increased likelihood of psychological distress in all study participants, when compared with permanently/ self-employed Swedish-born men (table 4). Permanently/ self-employed and temporarily employed non-refugee men were an exception. A striking increase in the 
Table 2 Crude and adjusted OR and $95 \%$ Cls for psychological distress (GHQ-12 scoring $\geq 3$ ) by employment status in 51118 individuals with data available for all covariates, stratified by migration status and reason for immigration: the Stockholm County public health surveys, 2002, 2006 and 2010

\begin{tabular}{|c|c|c|c|c|c|}
\hline \multirow[b]{2}{*}{ Employment status } & \multirow[b]{2}{*}{$\begin{array}{l}\text { Total sample }(n=51118) \\
\text { OR }(95 \% \mathrm{Cl})\end{array}$} & \multicolumn{2}{|l|}{ Migration status } & \multicolumn{2}{|l|}{ Reason for immigration } \\
\hline & & $\begin{array}{l}\text { Swedish-born ( } n=43444) \\
\text { OR }(95 \% \mathrm{Cl})\end{array}$ & $\begin{array}{l}\text { All immigrants }(n=7674) \\
\text { OR }(95 \% \mathrm{Cl})\end{array}$ & $\begin{array}{l}\text { Non-refugees }(n=4055) \\
\text { OR }(95 \% \mathrm{Cl})\end{array}$ & $\begin{array}{l}\text { Refugees }(\mathrm{n}=3619) \\
\text { OR }(95 \% \mathrm{Cl})\end{array}$ \\
\hline \multicolumn{6}{|l|}{ Crude } \\
\hline Permanently/self-employed (REF) & 1.00 & 1.00 & 1.00 & 1.00 & 1.00 \\
\hline Temporarily employed & 1.74 (1.62 to 1.88$)$ & 1.70 (1.56 to 1.84$)$ & 1.86 (1.57 to 2.20$)$ & $1.60(1.21$ to 2.11$)$ & 1.89 (1.52 to 2.35$)$ \\
\hline Unemployed & 3.28 (2.93 to 3.68$)$ & 3.23 (2.83 to 3.69$)$ & 3.22 (2.60 to 4.00$)$ & 3.59 (2.52 to 5.12$)$ & 2.83 (2.15 to 3.72$)$ \\
\hline \multicolumn{6}{|l|}{ Model $1^{*}$} \\
\hline Temporarily employed & 1.33 (1.23 to 1.44$)$ & $1.23(1.12$ to 1.35$)$ & $1.60(1.34$ to 1.90$)$ & 1.33 (1.00 to 1.77$)$ & 1.69 (1.35 to 2.10$)$ \\
\hline Unemployed & 3.15 (2.80 to 3.54$)$ & 3.00 (2.61 to 3.43$)$ & 3.19 (2.56 to 3.97$)$ & 3.48 (2.42 to 5.00$)$ & 2.86 (2.17 to 3.78$)$ \\
\hline \multicolumn{6}{|l|}{ Model $2 \dagger$} \\
\hline Temporarily employed & $1.33(1.23$ to 1.45$)$ & $1.23(1.13$ to 1.35$)$ & 1.59 (1.34 to 1.90$)$ & 1.33 (1.00 to 1.77$)$ & 1.69 (1.35 to 2.10$)$ \\
\hline Unemployed & 3.20 (2.85 to 3.60$)$ & 3.07 (2.68 to 3.52 ) & 3.20 (2.56 to 3.99$)$ & 3.49 (2.43 to 5.00$)$ & 2.87 (2.17 to 3.79$)$ \\
\hline \multicolumn{6}{|l|}{ Model 3ł } \\
\hline Temporarily employed & 1.33 (1.23 to 1.45$)$ & $1.24(1.13$ to 1.36$)$ & 1.60 (1.34 to 1.92$)$ & $1.36(1.01$ to 1.81$)$ & 1.71 (1.37 to 2.15$)$ \\
\hline Unemployed & 3.14 (2.78 to 3.53$)$ & 3.05 (2.66 to 3.51$)$ & 3.18 (2.54 to 3.98$)$ & 3.51 (2.44 to 5.05$)$ & 2.91 (2.20 to 3.85$)$ \\
\hline
\end{tabular}

All models are weighted for non-response and sampling methods.

*Model 1: adjusted for age and gender.

†Model 2: additionally adjusted for attained education

$\ddagger$ Model 3: additionally adjusted for socioeconomic position, disposable family income and survey year.

GHQ, the General Health Questionnaire; REF, reference group.

Table 3 Crude and adjusted OR and 95\% Cls for psychological distress (GHQ-12 scoring $\geq 3$ ) by employment status in 23708 men and 27410 women with data available for all covariates, stratified by migration status and reason for immigration: the Stockholm County public health surveys, 2002, 2006 and 2010

\begin{tabular}{|c|c|c|c|c|c|c|}
\hline \multirow[b]{2}{*}{ Employment status } & \multicolumn{2}{|l|}{ Swedish-born } & \multicolumn{2}{|l|}{ Non-refugees } & \multicolumn{2}{|l|}{ Refugees } \\
\hline & $\begin{array}{l}\text { Men }(n=20162) \\
\text { OR }(95 \% \mathrm{Cl})\end{array}$ & $\begin{array}{l}\text { Women }(n=23282) \\
\text { OR }(95 \% \mathrm{Cl})\end{array}$ & $\begin{array}{l}\text { Men }(n=1704) \\
\text { OR }(95 \% \mathrm{Cl})\end{array}$ & $\begin{array}{l}\text { Women }(n=2351) \\
\text { OR }(95 \% \mathrm{Cl})\end{array}$ & $\begin{array}{l}\text { Men }(n=1842) \\
\text { OR }(95 \% \mathrm{Cl})\end{array}$ & $\begin{array}{l}\text { Women }(n=1777) \\
\text { OR }(95 \% \mathrm{Cl})\end{array}$ \\
\hline \multicolumn{7}{|l|}{ Crude } \\
\hline Permanently/self-employed (REF) & 1.00 & 1.00 & 1.00 & 1.00 & 1.00 & 1.00 \\
\hline Temporarily employed & $1.70(1.46$ to 1.97$)$ & $1.55(1.40$ to 1.71$)$ & 1.64 (1.01 to 2.65$)$ & 1.54 (1.11 to 2.15$)$ & 1.75 (1.25 to 2.47$)$ & 1.85 (1.40 to 2.45$)$ \\
\hline Unemployed & 3.64 (2.97 to 4.45$)$ & 2.89 (2.42 to 3.45$)$ & 3.90 (2.29 to 6.63$)$ & 3.36 (2.08 to 5.41$)$ & 3.52 (2.42 to 5.13$)$ & $2.18(1.47$ to 3.25$)$ \\
\hline \multicolumn{7}{|l|}{ Model $1^{*}$} \\
\hline Temporarily employed & 1.35 (1.15 to 1.58$)$ & $1.16(1.04$ to 1.29$)$ & 1.30 (0.79 to 2.13$)$ & 1.35 (0.96 to 1.90$)$ & 1.69 (1.19 to 2.38$)$ & 1.65 (1.24 to 2.19$)$ \\
\hline Unemployed & 3.43 (2.80 to 4.21$)$ & 2.63 (2.20 to 3.13$)$ & 3.92 (2.29 to 6.71$)$ & $3.19(1.96$ to 5.18$)$ & 3.55 (2.44 to 5.18$)$ & $2.13(1.43$ to 3.18$)$ \\
\hline \multicolumn{7}{|l|}{ Model $2 \dagger$} \\
\hline Temporarily employed & 1.35 (1.16 to 1.58$)$ & 1.16 (1.04 to 1.29$)$ & 1.30 (0.79 to 2.13$)$ & 1.35 (0.96 to 1.90$)$ & 1.69 (1.19 to 2.39$)$ & 1.68 (1.25 to 2.22$)$ \\
\hline Unemployed & 3.55 (2.90 to 4.36$)$ & 2.67 (2.24 to 3.18$)$ & 3.92 (2.29 to 6.69$)$ & 3.20 (1.97 to 5.20$)$ & 3.65 (2.50 to 5.33$)$ & 2.11 (1.42 to 3.13$)$ \\
\hline \multicolumn{7}{|l|}{ Model $3 \ddagger$} \\
\hline Temporarily employed & $1.35(1.15$ to 1.59$)$ & $1.17(1.05$ to 1.31$)$ & 1.30 (0.78 to 2.18$)$ & 1.35 (0.96 to 1.92$)$ & $1.74(1.21$ to 2.48$)$ & 1.65 (1.23 to 2.22$)$ \\
\hline Unemployed & 3.54 (2.87 to 4.37$)$ & 2.65 (2.22 to 3.18$)$ & 3.88 (2.26 to 6.65$)$ & 3.46 (2.11 to 5.69$)$ & 3.78 (2.57 to 5.56$)$ & 2.14 (1.44 to 3.20$)$ \\
\hline $\begin{array}{l}\text { All models are weighted for non-resp } \\
\text { *Model 1: adjusted for age. } \\
\text { †Model 2: additionally adjusted for at } \\
\text { †Model 3: additionally adjusted for sc } \\
\text { GHQ, the General Health Questionn }\end{array}$ & $\begin{array}{l}\text { and sampling metho } \\
\text { education. } \\
\text { onomic position, dis } \\
\text { EF, reference group }\end{array}$ & family income and & year. & & & \\
\hline
\end{tabular}

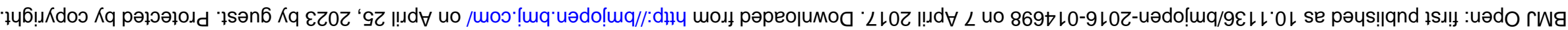


Table 4 Adjusted OR and Bonferroni-adjusted 95\% Cls for psychological distress (GHQ-12 scoring $\geq 3$ ) in pairwise comparison postestimation analysis among 51 118 individuals with data available for all covariates: the Stockholm County public health surveys, 2002, 2006 and 2010

\begin{tabular}{|c|c|c|c|c|c|c|c|}
\hline \multirow[b]{2}{*}{$\begin{array}{l}\text { Comparison groups in } \\
\text { pairwise comparison }\end{array}$} & \multirow{2}{*}{$\begin{array}{l}\text { Non-shared employment, } \\
\text { gender, migration } \\
\text { OR }(95 \% \mathrm{Cl})^{\star} \dagger\end{array}$} & \multirow{2}{*}{$\begin{array}{l}\text { Shared } \\
\text { employment } \\
\text { OR }(95 \% \mathrm{Cl})^{\star} \dagger\end{array}$} & \multicolumn{2}{|l|}{ Shared gender } & \multicolumn{3}{|c|}{ Shared migration status and reasons for immigration } \\
\hline & & & $\begin{array}{l}\text { Men } \\
\text { OR }(95 \% \mathrm{Cl})^{\star} \dagger\end{array}$ & $\begin{array}{l}\text { Women } \\
\text { OR }(95 \% \mathrm{Cl})^{\star} \dagger\end{array}$ & $\begin{array}{l}\text { Swedish-born } \\
\text { OR }(95 \% \mathrm{CI})^{\star} \dagger\end{array}$ & $\begin{array}{l}\text { Non-refugees } \\
\text { OR }(95 \% \mathrm{Cl})^{\star} \dagger\end{array}$ & $\begin{array}{l}\text { Refugees } \\
\text { OR }(95 \% \mathrm{Cl})^{\star} \dagger\end{array}$ \\
\hline \multicolumn{8}{|c|}{ Permanently/self-employed } \\
\hline Swedish men & 1.00 (REF) & 1.00 (REF) & 1.00 (REF) & & 1.00 (REF) & & \\
\hline Swedish women & 1.75 (1.56 to 1.96$)$ & $1.75(1.56$ to 1.96$) \ddagger$ & & 1.00 (REF) & $1.71(1.52$ to 1.92$) \ddagger$ & & \\
\hline Non-refugee men & $1.19(0.88$ to 1.61$)$ & $1.19(0.88$ to 1.61$) \ddagger$ & $1.19(0.88$ to 1.61$) \ddagger$ & & & 1.00 (REF) & \\
\hline Non-refugee women & $1.53(1.19$ to 1.95$)$ & $1.53(1.19$ to 1.95$) \ddagger$ & & 0.88 (0.69 to 1.11$)$ & & $1.28(0.89$ to 1.84$)$ & \\
\hline Refugee men & $1.43(1.09$ to 1.89$)$ & $1.43(1.09$ to 1.89$) \ddagger$ & $1.43(1.09$ to 1.89$) \ddagger$ & & & & 1.00 (REF) \\
\hline Refugee women & 2.29 (1.76 to 2.99$)$ & $2.29(1.76$ to 2.99$) \ddagger$ & & $1.31(1.01$ to 1.70$)$ & & & $1.60(1.12$ to 2.29$)$ \\
\hline \multicolumn{8}{|l|}{ Temporarily employed } \\
\hline Swedish men & 1.42 (1.07 to 1.89$)$ & 1.00 (REF) & $1.42(1.07$ to 1.89$) \ddagger$ & & $1.42(1.07$ to 1.89$) \ddagger$ & & \\
\hline Swedish women & $2.20(1.79$ to 2.70$)$ & $1.54(1.13$ to 2.13$)$ & & $1.26(1.04$ to 1.53$)$ & $2.20(1.79$ to 2.70$) \ddagger$ & & \\
\hline Non-refugee men & $1.63(0.70$ to 3.81$)$ & $1.15(0.47$ to 2.78$)$ & $1.63(0.70$ to 3.81$) \ddagger$ & & & 1.37 (0.56 to 3.33$)$ & \\
\hline Non-refugee women & $1.96(1.10$ to 3.51$)$ & $1.38(0.73$ to 2.60$)$ & & 1.12 (0.63 to 2.00$)$ & & $1.64(0.86$ to 3.12$)$ & \\
\hline Refugee men & 2.39 (1.32 to 4.30$)$ & $1.68(0.88$ to 3.18$)$ & $2.39(1.32$ to 4.30$) \ddagger$ & & & & $1.67(0.88$ to 3.14$)$ \\
\hline Refugee women & 3.71 (2.31 to 5.95$)$ & 2.61 (1.53 to 4.45$)$ & & 2.13 (1.33 to 3.39$)$ & & & 2.59 (1.53 to 4.39$)$ \\
\hline \multicolumn{8}{|l|}{ Unemployed } \\
\hline Swedish men & 3.75 (2.57 to 5.48$)$ & 1.00 (REF) & 3.75 (2.57 to 5.48$) \ddagger$ & & 3.75 (2.57 to 5.48$) \ddagger$ & & \\
\hline Swedish women & 4.81 (3.44 to 6.73$)$ & $1.28(0.89$ to 2.08$)$ & & 2.76 (1.99 to 3.83$)$ & 4.81 (3.44 to 6.73$) \ddagger$ & & \\
\hline Non-refugee men & 4.64 (1.76 to 12.27$)$ & 1.24 (0.44 to 3.48$)$ & 4.64 (1.76 to 12.3$) \ddagger$ & & & 3.89 (1.42 to 10.66$)$ & \\
\hline Non-refugee women & $4.87(2.02$ to 11.78$)$ & $1.30(0.50$ to 3.36$)$ & & 2.79 (1.16 to 6.73$)$ & & 4.08 (1.62 to 10.27$)$ & \\
\hline Refugee men & 5.30 (2.73 to 10.78$)$ & 1.41 (0.67 to 2.99$)$ & $5.30(2.73$ to 10.8$) \ddagger$ & & & & 3.70 (1.83 to 7.47$)$ \\
\hline Refugee women & 4.98 (2.48 to 10.00$)$ & 1.33 (0.61 to 2.90$)$ & & 2.85 (1.43 to 5.71$)$ & & & 3.48 (1.67 to 7.26$)$ \\
\hline
\end{tabular}

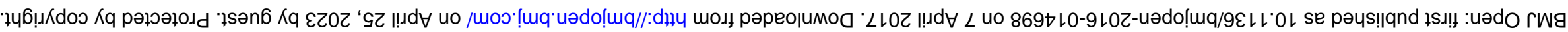


likelihood of psychological distress among unemployed individuals persisted in all comparison groups if permanently/self-employed counterparts were the reference. Within the categories of permanently/self-employed and temporarily employed individuals, the highest likelihood of distress was detected in women with refugee and Swedish background when compared with Swedish-born men (table 4 'Shared employment'). Missing data on employment status or psychological distress were associated with low education, unskilled SEP, very low family income and refugee status $(p<0.001)$. Additionally, females were more likely not to provide data on employment status compared with male respondents $(\mathrm{p}=0.04)$ (data not shown).

In a sensitivity analysis, the use of alternative cut-off (GHQ scoring $\geq 7$ ) did not alter the results (data not shown). Nor were any results altered when family structure was controlled for (data not shown).

\section{DISCUSSION}

Our study provides evidence that unemployment and temporary employment are associated with psychological distress. When compared with permanently/ self-employment status, unemployment is found to be related to an increased likelihood of distress across the whole study sample regardless of migration status, reason for immigration and gender with the effect only marginally attenuated by demographic and socioeconomic determinants. Temporary employment is associated with an increased likelihood of psychological distress, particularly in refugees and Swedish-born. The results were further strengthened when the difference in baseline odds was taken into consideration. Swedish and refugee women belonging to temporarily and permanently/self-employed groups evidenced higher odds of psychological distress compared with their male counterparts. Non-refugee men, whether employed permanently/self or temporarily, seem to go without excess risk of distress.

Our findings of association between unemployment and psychological distress are consistent with evidence from systematic reviews and meta-analyses, though the reviews did not focus on the impact of migration-related determinants. ${ }^{10} 1153$ Known as one of the strongest stressors, unemployment is considered to be similar to bereavement with regard to its negative effect on psychological health. ${ }^{10}$ It has been shown that the experience of unemployment may trigger a bulk of additional behavioural and social stressors that, in turn, further affect mental health. ${ }^{11}$

Though the underlying mechanisms of psychological distress remain unclear, it has been suggested that immigrants may be particularly at risk, as their exposure to migration-related stressors is coupled with unfavourable socioeconomic circumstances and potential challenges regarding integration. ${ }^{16}$ Our results, however, portray unemployment to be equally contributing to psychological health inequalities among Swedish-born and foreign-born groups. Likewise, a German study ${ }^{31}$ showed that unemployment increased the risk of psychological distress among Turkish immigrants and German-born. In contrast, Finnish ${ }^{19}$ and Dutch ${ }^{32}$ studies reported a more pronounced risk of impaired psychological health among unemployed native-born individuals with lower or no risk observed in unemployed multiethnic foreign-born groups. Dissimilarities in risks of psychological distress among unemployed immigrants have been noted in relation to ethnicity, country of birth and refugee status; however, evidence of the modification by ethnic background remains inconsistent, likely due to substantial heterogeneity. ${ }^{19} 202232$ Ethnicity may be seen as a proxy for culturally based behaviours and attitudes, exposure to stigmatisation and discrimination as well as for opportunity to enter and remain in the labour force. ${ }^{1}$ It has been suggested that immigrants born outside Europe, particularly refugees, may experience a higher burden of stressors, compounded by lower employment rates. ${ }^{54}$ In our study, the risk of psychological distress among unemployed did not appear to be modified by reason for immigration. Additional analysis performed among immigrants while controlling for being born in a non-OECD versus OECD country did not alter our results (data not shown). Neither did accounting for possible differences in integration by controlling for number of years spent in Sweden since the year of immigration (data not shown).

In immigrant studies, the role of gender in the association between employment and mental well-being also appears to be rather unclear. ${ }^{19} 2031$ Inconsistencies stem from a variety of health and social determinants that may act as risk and protective factors interacting with conventional gender roles that, in turn, may vary between different ethnic groups. Our data provide no evidence that gender modifies the risk of distress among unemployed individuals. We may assume that in our study population, the negative effect of unemployment on health overcomes gender-specific and migrationspecific differences. A qualitative study by Knocke ${ }^{55}$ reported that immigrants and Swedish-born are active in job-seeking and highly motivated for integrating into the labour market. This might explain why individuals, if excluded from the labour force, appear to be equally affected regardless of their migration status and gender.

The negative impact of temporary employment on psychological health should not be overlooked. Our results corroborate previous findings that employment instability is detrimental for physical and mental health. ${ }^{12} 1315{ }^{56}$ It has been shown that, in addition to uncertainty about the job situation, the temporarily employed may suffer from exposure to unhealthy physical and psychological work environments, low wages, lack of health insurance and social security and, not least, from powerlessness to counteract these pressures. ${ }^{12} 13$ No excess in likelihood of distress among nonrefugee immigrants seen in pairwise comparison might 
be potentially explained by non-refugees being 'working immigrants' for whom temporary employment can serve as a step to a permanent job.

Similar to the results reported by Lahelma $e t a l,{ }^{57}$ our study revealed no alterations in associations between employment status and psychological distress when severity of outcome was addressed by using two alternative cut-offs. The results, therefore, portray unemployment and temporary employment to be of importance for the whole spectrum of distress symptoms.

The strengths of our study include the large population-based sample with self-reported and registerbased data that allowed overcoming potential problems with statistical power in the stratified analyses. Additionally, the use of an intercultural-validated instrument for measuring distress reduced the impact of information bias. The application of survey weights ensured generalisability of the study results for Stockholm residents, who, in turn, are representative to other multiethnical urban populations in Sweden. Generalisability to European populations, though plausible, should be seen in relation to the country's level of unemployment, immigrant sociodemographic profile and welfare policies. Moreover, the use of weights and further adjustment for the survey year allowed to minimise potential heterogeneity in unemployed respondents, given that the surveys were undertaken over the period of global economic and financial crisis in 2008. It should, however, be mentioned that Sweden was less affected by the crisis and recovered sooner, also regarding the losses in employment, compared with other countries. ${ }^{58}$ Finally, the study benefited from a high survey participation rate observed among immigrants partially as a result of using translated versions of the questionnaire, reducing the risk of selection bias.

Some potential limitations stem from cross-sectional study design and have to be acknowledged. First, the design restricts testing temporality of study covariates, which creates an obstacle for making causal inferences and limits disentangling confounding and mediating effects. Second, the cross-sectional nature of data on employment status hampers our ability to assess the role of duration of unemployment that might have additionally explained the presence and severity of psychological distress. Third, in the light of the potential bidirectional relationship between unemployment and psychological distress, ${ }^{9}$ we cannot rule out attained employment to be influenced by mental conditions. We attempted to diminish this risk by initially excluding disability pensioners and individuals on long-term sick leave, as in Sweden, mental illnesses are the predominant grounds for both. To avoid measuring the potential long-term effect of adoption or the impact of stress related to actual migration processes rather than an association with current employment status, we excluded adopted individuals and immigrants with a history of inpatient mental care within their first 2 years of arrival to Sweden. Fourth, despite the low levels of missing data, non-response was higher among refugees and individuals with less favourable socioeconomic characteristics; therefore, possible underestimation of associations should be acknowledged. Finally, the reason for immigration variable was constructed based on the country of origin and year of immigration to Sweden and, thus, misclassification may occur if individuals from asylumseeking countries entered Sweden on other grounds. We, however, have tried to minimise the misclassification by testing our approach to defining the reason for immigration with Statistics Sweden and the Swedish Migration Boards. Thus, if present, the misclassification would not affect the comparison between Swedish-born and immigrants, but may dilute the effect among refugees.

In conclusion, despite the cross-sectional design, our results point to the importance of considering unemployed persons, regardless of migration status, reason for immigration and gender, as a target group for public health policies and actions aimed at preventing psychological health inequalities in contemporary Sweden. The impact of insecure employment on psychological health should likewise not be overlooked, particularly among Swedish-born and refugee. Owing to the complex interplay between social, migration-related and gender-related determinants of psychological distress, and the potential bidirectional association between distress and employment status, longitudinal research is needed to further investigate the individual and contextual factors that facilitate or disrupt these relationships.

Contributors AS, KE, NKL and JM conceptualised and designed the study and the empirical analysis. KE and CJ acquired data, conceptualised the variables and assisted with data management. NKL conducted a preliminary analysis, with support of CJ. AS carried out the main statistical analysis and drafted the initial manuscript. AS, KE and JM interpreted the results and critically reviewed the manuscript. All authors contributed to revising and editing the manuscript with substantial methodological and intellectual support and approved the manuscript as submitted.

Funding This work was supported by the Swedish Research Council for Health, Working Life and Welfare (FORTE) grant number 2014-2423.

Competing interests None declared.

Ethics approval The study was approved by the Stockholm Regional Ethical Review Board (number: 2006/1112-31 and 2012/1812-32).

Provenance and peer review Not commissioned; externally peer reviewed.

Data sharing statement No additional data are available.

Open Access This is an Open Access article distributed in accordance with the Creative Commons Attribution Non Commercial (CC BY-NC 4.0) license, which permits others to distribute, remix, adapt, build upon this work noncommercially, and license their derivative works on different terms, provided the original work is properly cited and the use is non-commercial. See: http:// creativecommons.org/licenses/by-nc/4.0/

\section{REFERENCES}

1. Drapeau A, Marchand A, Beaulieu-Prévost D. Epidemiology of psychological distress. In: Labate L, ed. Mental illnessesunderstanding, prediction and control. Rijeka, Croatia: InTech, 2012:105-34. 
2. Artazcoz L, Benach J, Borrell C, et al. Unemployment and mental health: understanding the interactions among gender, family roles, and social class. Am J Public Health 2004;94:82-8.

3. de Gelder R, Koster EM, van Buren LP, et al. Differences in adults health and health behaviour between 16 European urban areas and the associations with socio-economic status and physical and social environment. Eur J Public Health Published Online First: 8 Jun 2016. doi: https://doi.org/10.1093/eurpub/ckv141

4. Ahnquist J, Wamala SP, Lindstrom M. Social determinants of health-a question of social or economic capital? Interaction effects of socioeconomic factors on health outcomes. Soc Sci Med 2012;74:930-9.

5. Kosidou K, Dalman C, Lundberg M, et al. Socioeconomic status and risk of psychological distress and depression in the Stockholm Public Health Cohort: a population-based study. J Affect Disord 2011;134:160-7.

6. Rai D, Kosidou K, Lundberg M, et al. Psychological distress and risk of long-term disability: population-based longitudinal study. $J$ Epidemiol Community Health 2012;66:586-92.

7. Wadman C, Boström G, Karlsson AS. Health on equal terms? Results from the 2006 Swedish National Public Health Survey. Sweden: Swedish National Institute of Public Health, 2008.

8. Negrini A, Perron J, Corbiere M. The predictors of absenteeism due to psychological disability: a longitudinal study in the education sector. Work 2014;48:175-84.

9. van Rijn RM, Robroek SJ, Brouwer S, et al. Influence of poor health on exit from paid employment: a systematic review. Occup Environ Med 2014;71:295-301.

10. Luhmann M, Hofmann W, Eid M, et al. Subjective well-being and adaptation to life events: a meta-analysis. J Pers Soc Psychol 2012;102:592-615.

11. McKee-Ryan F, Song Z, Wanberg CR, et al. Psychological and physical well-being during unemployment: a meta-analytic study. $J$ Appl Psychol 2005:90:53-76.

12. Kim TJ, von dem Knesebeck $O$. Is an insecure job better for health than having no job at all? A systematic review of studies investigating the health-related risks of both job insecurity and unemployment. BMC Public Health 2015;15:985.

13. Virtanen M, Kivimaki M, Joensuu M, et al. Temporary employment and health: a review. Int J Epidemiol 2005;34:610-22.

14. Canivet $\mathrm{C}$, Bodin $\mathrm{T}$, Emmelin $\mathrm{M}$, et al. Precarious employment is a risk factor for poor mental health in young individuals in Sweden: a cohort study with multiple follow-ups. BMC Public Health 2016;16:687.

15. Flint $\mathrm{E}$, Bartley $\mathrm{M}$, Shelton $\mathrm{N}$, et al. Do labour market status transitions predict changes in psychological well-being? J Epidemiol Community Health 2013;67:796-802.

16. Thoits PA. Stress and health: major findings and policy implications. $J$ Health Soc Behav 2010;51:S41-53.

17. Frasquilho D, de Matos MG, Marques A, et al. Distress and unemployment: the related economic and noneconomic factors in a sample of unemployed adults. Int J Public Health 2016;61: $821-8$

18. Kosidou K, Hellner-Gumpert C, Fredlund $\mathrm{P}$, et al. Immigration, transition into adult life and social adversity in relation to psychological distress and suicide attempts among young adults. PLOS ONE 2012;7:e46284

19. Rask S, Suvisaari J, Koskinen S, et al. The ethnic gap in mental health: a population-based study of Russian, Somali and Kurdish origin migrants in Finland. Scand $J$ Public Health 2016;44:281-90.

20. Straiton M, Grant JF, Winefield HR, et al. Mental health in immigrant men and women in Australia: the North West Adelaide Health Study. BMC Public Health 2014:14:1111.

21. Syed HR, Dalgard OS, Dalen I, et al. Psychosocial factors and distress: a comparison between ethnic Norwegians and ethnic Pakistanis in Oslo, Norway. BMC Public Health 2006;6:182.

22. Tinghog $\mathrm{P}$, Hemmingsson $\mathrm{T}$, Lundberg I. To what extent may the association between immigrant status and mental illness be explained by socioeconomic factors? Soc Psychiatry Psychiatr Epidemiol 2007:42:990-6.

23. Sundquist J. Refugees, labour migrants and psychological distress. A population-based study of 338 Latin-American refugees, 161 south European and 396 Finnish labour migrants, and 996 Swedish age-, sex- and education-matched controls. Soc Psychiatry Psychiatr Epidemiol 1994;29:20-4.

24. Statistics Sweden. Summary of Population Statistics 1960-2015 http://www.scb.se/en/finding-statistics/statistics-by-subject-area/ population/population-composition/population-statistics/pong/ tables-and-graphs/yearly-statistics--the-whole-country/summary-ofpopulation-statistics-19602015/ (accessed 16 Dec 2016).

25. United Nations, Department of Economic and Social Affairs, Population Division. International Migration Report 2015: Highlights, 2016. http://www.un.org/en/development/desa/population/migration/ publications/migrationreport/docs/MigrationReport2015_Highlights. pdf (accessed 16 Dec 2016).

26. Lemaître G. The integration of immigrants into the labour market: the case of Sweden. OECD Social, Employment and Migration Working Papers. 2007:48. http://www.oecd.org/els/38164205.pdf (accessed 15 Sep 2016)

27. Aldén L, Hammarstedt M. Integration of immigrants on the Swedish labour market-recent trends and explanations. Linnaeus University Centre for Labour Market and Discrimination Studies Working Papers 2014:9. http://Inu.se/polopoly_fs/1.107538!/LMDSWP20149_ mall.pdf (accessed 15 Sep 2016).

28. Hollander AC, Bruce D, Ekberg J, et al. Hospitalisation for depressive disorder following unemployment-differentials by gender and immigrant status: a population-based cohort study in Sweden. J Epidemiol Community Health 2013;67:875-81.

29. Bogic M, Njoku A, Priebe S. Long-term mental health of war-refugees: a systematic literature review. BMC Int Health Hum Rights 2015;15:29.

30. Shishehgar S, Gholizadeh L, DiGiacomo M, et al. The impact of migration on the health status of Iranians: an integrative literature review. BMC Int Health Hum Rights 2015;15:20.

31. Aichberger MC, Bromand Z, Heredia Montesinos A, et al. Socio-economic status and emotional distress of female Turkish immigrants and native German women living in Berlin. Eur Psychiatry 2012;27(Suppl 2):S10-16.

32. Schuring $M$, Burdorf $A$, Kunst $A$, et al. Ethnic differences in unemployment and ill health. Int Arch Occup Environ Health 2009;82:1023-30.

33. Hollander AC, Dal H, Lewis G, et al. Refugee migration and risk of schizophrenia and other non-affective psychoses: cohort study of 1.3 million people in Sweden. BMJ 2016;352:i1030.

34. Lindert J, Ehrenstein OS, Priebe S, et al. Depression and anxiety in labor migrants and refugees-a systematic review and meta-analysis. Soc Sci Med 2009;69:246-57.

35. Svensson AC, Fredlund $\mathrm{P}$, Laflamme L, et al. Cohort profile: the Stockholm Public Health Cohort. Int J Epidemiol 2013;42:1263-72.

36. Moradi T, Sidorchuk A, Hallqvist J. Translation of questionnaire increases the response rate in immigrants: filling the language gap or feeling of inclusion? Scand J Public Health 2010;38:889-92

37. Schwarzwald H, Mongomery Collins E, Gillespie S, et al. International adoption and clinical practice. Switzerland: Springer International Publishing, 2015.

38. Goldberg DP, Williams P. A user's guide to the General Health Questionnaire. Berkshire, UK: NFER-Nelson Publishing Company, 1988.

39. Furukawa T, Goldberg DP. Cultural invariance of likelihood ratios for the General Health Questionnaire. Lancet 1999;353:561-2.

40. Goldberg DP, Gater R, Sartorius N, et al. The validity of two versions of the GHQ in the WHO study of mental illness in general health care. Psychol Med 1997;27:191-7.

41. Werneke U, Goldberg DP, Yalcin I, et al. The stability of the factor structure of the General Health Questionnaire. Psychol Med 2000;30:823-9

42. Gotsens $\mathrm{M}$, Malmusi D, Villarroel $\mathrm{N}$, et al. Health inequality between immigrants and natives in Spain: the loss of the healthy immigrant effect in times of economic crisis. Eur J Public Health 2015;25:923-9.

43. Lundin A, Hallgren M, Theobald $\mathrm{H}$, et al. Validity of the 12-item version of the General Health Questionnaire in detecting depression in the general population. Public Health 2016;136:66-74.

44. Mirowsky J, Ross CE. Measurement for a human science. J Health Soc Behav 2002;43:152-70.

45. Laaksonen E, Martikainen $\mathrm{P}$, Lahelma E, et al. Socioeconomic circumstances and common mental disorders among Finnish and British public sector employees: evidence from the Helsinki Health Study and the Whitehall II Study. Int J Epidemiol 2007;36:776-86.

46. Eurofound. European Foundation for improvement of living and working conditions. Sweden: Self-employed workers, 2009. http:/ www.eurofound.europa.eu/observatories/eurwork/ comparative-information/national-contributions/sweden/ sweden-self-employed-workers (accessed 17 Dec 2016)

47. Samuelsson A, Houkes I, Verdonk P, et al. Types of employment and their associations with work characteristics and health in 
Swedish women and men. Scand J Public Health 2012:40:183-90.

48. Diderichsen F, Andersen I, Manuel C, et al. Health inequalitydeterminants and policies. Scand J Public Health 2012;40(8 Suppl):12-105.

49. Buffel V, Van de Velde S, Bracke P. The mental health consequences of the economic crisis in Europe among the employed, the unemployed, and the non-employed. Soc Sci Res 2015;54:263-88.

50. Urbanos-Garrido RM, Lopez-Valcarcel BG. The influence of the economic crisis on the association between unemployment and health: an empirical analysis for Spain. Eur J Health Econ 2015;16:175-84.

51. Ai C, Norton EC. Interaction terms in logit and probit models. Econ Lett 2003;80:123-9.

52. Buis ML. Stata tip 87: interpretation of interaction in nonlinear models. Stata J 2010;10:305-8.
53. Murphy GC, Athanasou JA. The effect of unemployment on mental health. J Occup Organ Psychol 1999;72:83-99.

54. Lundborg P. Refugees' employment integration in Sweden: cultural distance and labor market performance. Rev Int Econ 2013;21:219-32.

55. Knocke W. Integration or segregation? Immigrant populations facing the labour market in Sweden. EID 2000;21:361-80.

56. Robert G, Martinez JM, Garcia AM, et al. From the boom to the crisis: changes in employment conditions of immigrants in Spain and their effects on mental health. Eur J Public Health 2014;24:404-9.

57. Lahelma E, Laaksonen M, Martikainen $\mathrm{P}$, et al. Multiple measures of socioeconomic circumstances and common mental disorders. Soc Sci Med 2006;63:1383-99.

58. OECD. Economic Surveys SWE. DEN Overview. 2015. http://www. oecd.org/eco/surveys/economic-survey-sweden.htm (accessed 17 Dec 2016) 